\title{
On data transformations and evidence of nonlinearity
}

\author{
Paul DE BRUIN* \\ Tinbergen Institute Amsterdam \\ University of Amsterdam \\ and \\ Philip Hans FRANSES \\ Econometric Institute \\ Erasmus University Rotterdam
}

June 1998

Econometric Institute Report 9823/A

\begin{abstract}
In this paper we examine the interaction between data transformation and the empirical evidence obtained when testing for (non-)linearity. For this purpose we examine nonlinear features in 64 monthly and 53 quarterly US macroeconomic variables for a range of Box-Cox data transformations. Our general finding is that evidence of nonlinearity is not independent of the data transformation. Results of simulation experiments substantiate this finding.

*Corresponding author: University of Amsterdam, Roetersstraat 11, 1018 WB Amsterdam, Fax: +3120-5254349, e-mail: pdebruin@fee.uva.nl. We thank participants of a seminar at the Tinbergen Institute Amsterdam for many helpful comments.
\end{abstract}




\section{Introduction}

At present there is a growing interest in considering nonlinear time series models for macroeconomic variables. Important studies that stimulated this interest are Granger and Teräsvirta (1993), Tong (1990) and Hamilton (1989), to mention just a few. Examples of empirically useful models are the Markov regime switching model (Hamilton, 1989) and the so-called Smooth Transition Autoregression [STAR] (Teräsvirta, 1994). These models allow for a description of time series that undergo various regimes, such as recessions and expansions.

Most empirical time series models are considered for data which are natural log transformed, which is one of the Box-Cox transformations, see Box and Cox (1964). Usually, this transformation is applied because it is presumed to remove nonstationarity or heteroscedasticity from the data, and that it induces symmetry and perhaps normality to the probability distribution of the time series variable in question. A casual glance at much empirical work in macroeconomics shows that the log-transformation is usually routinely applied, and that its presumed properties are seldom verified. Of course, another reason

for applying the log transform is the fact that sometimes one is interested in the growth rate of a variable rather than in its level, where the growth rate roughly corresponds with first differenced logged data.

As is well known, the Box-Cox transformation is a nonlinear transformation. Therefore it is interesting to understand how this transformation influences characteristics in the data, and particularly, possible nonlinear properties. On the other hand, it may be that this transformation introduces nonlinearity in linear data. In this paper we investigate the influence of a range of Box-Cox transformations on empirical evidence of nonlinearity in many macroeconomic variables. Our analysis does not assume a correct transformation that can be found by estimating the Box-Cox parameter in a nonlinear time series model. Instead, we analyze the properties of data for a range of Box-Cox parameters in order to study possible links between their values and empirical evidence of nonlinearity. We also use artificially generated series to study whether our empirical findings can be better understood. To save space, we focus our attention on tests for STAR type nonlinearity.

The outline of our paper is as follows. In section 2 we give a description of the time 
series variables we consider. Section 3 deals with a description of the data transformations and the nonlinearity test used. To allow for heteroscedasticity that increases or decreases over time, we also introduce and apply a GLS-based test for nonlinearity. Section 4 gives the results of the tests applied to the empirical data. In section 5 we utilize the same procedure again, but this time for artificially generated AR and STAR time series. Our main conclusion is that evidence of nonlinearity changes over the spectrum of Box-Cox parameter values. Our simulation results help us to explain part of these findings. For some empirical time series we reject linearity for all Box-Cox values, implying that the practitioner has a free choice which data transformation to consider. In section 6 we conclude our paper with some remarks.

\section{Data}

In our empirical work we consider 53 quarterly time series and 64 monthly time series. These monthly series will also be analyzed in quarterly aggregated form. The monthly data sets can be divided as Monetary Issues (28), Employment (24) and Income and Expenditures (12). All quarterly data concern Production variables. All data can be obtained from the website www.stls.frb.org/fred/data/. Since we are investigating the interaction between nonlinearity aspects of the data and nonlinear transformations, we do not want seasonal effects influencing the outcomes. Therefore, we only use data that are already seasonally adjusted. Using seasonally adjusted data also ensures that the auxiliary test regressions for nonlinearity do not contain too many parameters. We are however familiar with the results in Ghysels, Granger and Siklos (1996) and Franses and Paap (1999), where it is documented that seasonal adjustment may introduce nonlinearity in otherwise linear time series, and that it changes the key parameters in nonlinear models, respectively.

A description of the monthly data is given in Tables 1,2 and 3. The quarterly data are described in Table 4. The length of the monthly data sets differs from 282 to 622 months. All quarterly time series are a little over 150 data long. We assume that in all cases the size of the data sets is large enough to be able to make well-founded inference. 


\section{Empirical methodology}

Consider a time series variable $x_{t},(t=1, \ldots, T)$, where $x_{t}$ cannot have negative or zero observations. The family of Box-Cox transformations is given by:

$$
y_{\lambda, t}= \begin{cases}\frac{x_{t}^{\lambda}-1}{\lambda} & \text { for } 0<\lambda<1 \\ \ln \left(x_{t}\right) & \text { for } \lambda=0\end{cases}
$$

where the transformation for $\lambda=0$ follows from the fact that $\lim _{\lambda \rightarrow 0} \frac{x_{t}^{\lambda}-1}{\lambda}=\ln \left(x_{t}\right)$. Subtracting 1 and dividing by $\lambda$ does not influence the stochastic structure of $x_{t}^{\lambda}$, and hence one often considers the transformation:

$$
y_{\lambda, t}= \begin{cases}x_{t}^{\lambda} & \text { for } 0<\lambda<1 \\ \ln \left(x_{t}\right) & \text { for } \lambda=0\end{cases}
$$

instead of (1), without loss of generality.

Many macroeconomic time series display an upward trend. Without further testing, we assume here for all values of $\lambda$ that this trend is a stochastic trend, and hence that we can induce stationarity of a time series $z_{t}$ by taking first differences, defined by

$$
\nabla z_{t}=z_{t}-z_{t-1}
$$

It appears that the decision on taking first differences can be affected by the Box-Cox data transformation, see Granger and Hallman (1991), Franses and Koop (1998) and Franses and McAleer (1998), for example. For simplicity, we abstain from a discussion on these matters, and assume that first differencing, at least approximately, removes a stochastic trend. In sum, we consider testing for nonlinearity in the time series:

$$
\nabla y_{\lambda, t}= \begin{cases}x_{t}^{\lambda}-x_{t-1}^{\lambda} & \text { for } 0<\lambda \leq 1 \\ \ln \left(x_{t}\right)-\ln \left(x_{t-1}\right) & \text { for } \lambda=0\end{cases}
$$

In this paper we choose $\lambda=0,0.05,0.10, \ldots, 1.00$. So, for every original time series $x_{t}$ we get 21 transformed series $\nabla y_{\lambda, t}$. For practical purposes one may conjecture that only a few values of $\lambda$ (like $0,1 / 2$ and 1 ) are relevant. However, we consider more such values in order to be able to better examine any systematic patterns across increasing and decreasing values of $\lambda$ and evidence of nonlinearity. 
To test for nonlinearity in $\nabla y_{\lambda, t}$, we consider the test for STAR advocated in Teräsvirta (1994). This test aims to discriminate between the linear autoregressive (AR) model

$$
y_{t}=\pi_{1}^{\prime} w_{t}+\eta_{t}
$$

where $y_{t}$ is shorthand for $\nabla y_{\lambda, t}$, as defined in (4), and the nonlinear logistic smooth transition autoregressive (LSTAR) model

$$
y_{t}=\pi_{1}^{\prime} w_{t}+f\left(\tilde{w}_{t} ; \gamma, a, c\right) \pi_{2}^{\prime} w_{t}+\eta_{t}
$$

where $f\left(\tilde{w}_{t} ; \gamma, a, c\right)=\left(1+\exp \left(-\gamma\left(a^{\prime} \tilde{w}_{t}-c\right)\right)\right)^{-1}-\frac{1}{2}, \pi_{i}^{\prime}=\left(\pi_{i 0}, \ldots, \pi_{i p}\right)$ for $i=1,2$, $\tilde{w}_{t}=\left(y_{t-1}, \ldots, y_{t-p}\right)^{\prime}, w_{t}=\left(1, \tilde{w}_{t}\right)^{\prime}, a=\left(a_{1}, \ldots, a_{p}\right)^{\prime}$. In both models $\eta_{t} \sim N\left(0, \sigma_{\eta}^{2}\right)$. By subtracting $\frac{1}{2}$ from the logistic function we get as the null hypothesis of linearity $H_{0}: \gamma=0$ with the alternative $H_{1}: \gamma>0$. Replacing $f\left(\tilde{w}_{t} ; \gamma, a, c\right)$ by a first order Taylor expansion, an empirically useful test procedure is as follows:

- Determine the value of $p$ by letting it run from 1 to $p_{\max }$ and choose that value for which the Akaike or Schwarz model selection criterion (AIC or BIC) attains its minimum value. In this paper we set $p_{\max }=4$.

- Regress $y_{t}$ on $w_{t}$ as in (5). Compute the residuals $\hat{\eta}_{t}=y_{t}-\hat{\pi}_{1}^{\prime} w_{t}$, and the sum of squares $S S R_{0}=\sum \hat{\eta}_{t}^{2}$.

- Estimate the parameters in the auxiliary regression

$$
\hat{\eta}_{t}=\phi^{\prime} w_{t}+\sum_{j=1}^{p} \sum_{i=1}^{j} \phi_{i j} \tilde{w}_{t i} \tilde{w}_{t j}+\nu_{t},
$$

where $\tilde{w}_{t i}$ and $\tilde{w}_{t j}$ are the $i$ th and $j$ th component of $\tilde{w}_{t}$ respectively. Compute the residual sum of squares $S S R_{1}=\sum \hat{\nu}_{t}^{2}$.

- Compute the test statistic

$$
L M=\frac{T\left(S S R_{0}-S S R_{1}\right)}{S S R_{0}}
$$

Under the null hypothesis of linearity, this LM test statistic has a $\chi^{2}\left(\frac{p(p+1)}{2}\right)$ distribution, see Teräsvirta (1994). 
The transformed series $\nabla y_{\lambda, t}$ in (4) may be heteroscedastic for some values of $\lambda$. This may disturb the outcome of the linearity test. Therefore, we propose and apply a linearity test that should be robust to some form of heteroscedasticity. This new test is based on applying GLS to the AR model for $\nabla y_{\lambda, t}$. Here, we assume that the residuals $\hat{\epsilon}_{t}$ are distributed as

$$
\epsilon_{t} \sim N\left(0, \sigma_{\epsilon, t}^{2}\right)
$$

where $\sigma_{\epsilon, t}^{2}=\exp \left(\alpha_{0}+\alpha_{1} t\right)$ for some unknown $\alpha_{0}$ and $\alpha_{1}$. This assumption includes the cases of homoscedasticity $\left(\alpha_{1}=0\right)$, exponentially growing variance $\left(\alpha_{1}>0\right)$ and exponentially decaying variance $\left(\alpha_{1}<0\right)$. We consider the following procedure:

- Fit an $\operatorname{AR}(p)$ to $\nabla y_{\lambda, t}$. In this paper, $p\left(\leq p_{\max }\right)$ is selected by the AIC only.

- Compute the residuals $\hat{\epsilon}_{t}$.

- Regress $\ln \left(\hat{\epsilon}_{t}^{2}\right)$ on a constant and time $t$. The regression parameters are $\hat{\alpha}_{0}$ and $\hat{\alpha}_{1}$.

- Calculate $\ln \widehat{\left(\sigma_{t}^{2}\right)}=\hat{\alpha}_{0}+\hat{\alpha}_{1} t$, and $\hat{\sigma}_{t}^{2}=\exp \left(\ln \widehat{\left(\sigma_{t}^{2}\right)}\right)$ for all $t$.

- Compute $z_{t}=y_{t} / \hat{\sigma}_{t}$. If the assumption on the form of heteroscedasticity is correct, this new time series variable is homoscedastic and therefore the above test procedure for nonlinearity can be applied to $z_{t}$.

In the next two sections we apply the two LM tests to variables $\nabla y_{\lambda, t}$, where we allow $\lambda$ to vary over a range of values for empirical and simulated data.

\section{Results}

In Tables 5 and 7 we give the results of the linearity test for the monthly data and the original quarterly data, respectively. The total number of monthly time series is 64 and we have 53 quarterly time series. The monthly data can also be aggregated to quarterly data. The results of the linearity test to these aggregated time series can be found in Table 6. The three tables have eight columns for each test for nonlinearity (OLS and GLS). For the first two columns the order $p$ in equation (5) is determined on the basis 
of the AIC and the level of significance for the LM test is 5\%. The first column gives the results for all available time series. The second column gives the results for those series for which linearity is rejected for $\lambda=0$. The third and fourth column again use the AIC but this time the level of significance is $10 \%$. Again, the third column concerns alle series, while the fourth column concerns only those series for which for $\lambda=0$ linearity is rejected. This also applies to columns six and eight for each test. In the fifth and sixth column we select the optimal AR order by the BIC, with a test level of $5 \%$. In the last two columns again BIC is used with the level of significance put to $10 \%$.

The results in Tables 5, 6 and 7 lead to several conclusions. The first is that the GLSbased test finds slightly less nonlinearity, as compared with the OLS-based test. Also, when BIC is used to select $p$ we find slightly less evidence of nonlinearity than in case we use the AIC. A cause for this may be that BIC generally finds lower values of $p$. As a consequence, less regressors are included in the auxiliary regression of the linearity test, and thus nonlinearity may be more difficult to find.

The second result, based on comparing the percentage of series with evidence of nonlinearity in Tables 6 and 7 versus Table 5, is that we find more nonlinearity in monthly data than in quarterly data. This substantiates earlier findings in empirical work that perhaps one may opt for fitting nonlinear time series models to monthly data instead of to quarterly data.

With respect to the Box-Cox parameter we find mixed results across Tables 5, 6 and 7. For the monthly data we find most evidence of nonlinearity (in more than $60 \%$ of the cases) for $\lambda$ taking values close to 0 or 1 . The rejection frequencies display a certain Ushaped pattern, where minimum evidence of nonlinearity is found for $\lambda$ close to $1 / 2$. This may be partly due to heteroscedasticity for $\lambda$ close to 1 . When applying GLS this U-shape disappears. In that case we find slightly less evidence of nonlinearity for larger values of $\lambda$. For the quarterly data, however, we find more evidence of nonlinearity for larger values of $\lambda$. Additionally, if we consider all even columns of Tables 5, 6 and 7, that is those columns where nonlinearity is detected for those series with nonlinearity features for $\lambda=0$, we obtain intruiging outcomes. It appears that when $\ln \left(x_{t}\right)-\ln \left(x_{t-1}\right)$ is nonlinear, evidence of nonlinearity for $x_{t}^{\lambda}-x_{t-1}^{\lambda}$ tends to decrease, but not much. Hence, in some cases, the differenced levels can perhaps be described by a linear model instead of a nonlinear model. 
For these series it may hold true that the log transformation introduces nonlinearity.

In sum, we find that evidence of nonlinearity changes with the value of the Box-Cox parameter. In the next section we will use simulation experiments to examine if the patterns observed in Tables 5, 6 and 7 can be replicated.

\section{Simulations}

In this section we study the performance of the LM tests for linearity across various values of $\lambda$ in a controlled simulation experiment. We first consider the tests in case the data $y_{t}$ are linear. Next, we study the case of nonlinear data.

We act as though a time series $y_{t}$ is the result of a transformation of $x_{t}$ by $y_{t}=x_{t}-x_{t-1}$ (indicated by $\lambda=1$ ) or a transformation $y_{t}=\ln \left(x_{t}\right)-\ln \left(x_{t-1}\right)$ (indicated by $\lambda=0$ ) respectively. Hence, from $y_{t}$ we construct $x_{t}$ by $x_{t}=y_{t}+x_{t-1}$ or $x_{t}=\exp \left(y_{t}\right) * x_{t-1}$ respectively. We need a starting value for $x_{0}$. We can choose it freely, conditional on $x_{t}>0$ for all $t$. As soon as the artificial time series $x_{t}$ is constructed, we can deal with it the same way we did with the real time series in the former section. That is, we transform it to $\nabla y_{\lambda, t}=x_{t}^{\lambda}-x_{t-1}^{\lambda}$ for $\lambda=0,0.05, \ldots, 1.00$ and apply the linearity tests of section 3 to all 21 transformed series.

The data generating process (DGP) we use in the first set of experiments is an AR model. This way we can answer the question: if the DGP is linear, can values of $\lambda$ be found where the linearity test concludes nonlinearity for $y_{\lambda, t}$ ? We choose the AR processes as:

$$
\begin{aligned}
& \text { Model 1: } \lambda=1, \quad y_{t}=y_{t-1}-0.8 y_{t-2}+\epsilon_{t}, \quad x_{0}=10 \\
& \text { Model 2: } \quad \lambda=1, \quad y_{t}=0.02+0.9 y_{t-1}-0.795 y_{t-2}+\epsilon_{t}, \quad x_{0}=10 \\
& \text { Model 3: } \lambda=0, \quad y_{t}=y_{t-1}-0.8 y_{t-2}+\epsilon_{t}, \quad x_{0}=1 \\
& \text { Model 4: } \quad \lambda=0, \quad y_{t}=0.02+0.9 y_{t-1}-0.795 y_{t-2}+\epsilon_{t}, \quad x_{0}=0.1
\end{aligned}
$$

From every model we generate 1000 realisations of length 300 and count the number of times we reject linearity. The result of this exercise can be found in Tables 8 - 11. From the last rows of Tables 8 and 9, and the first rows of Tables 10 and 11, we notice that the empirical size of the test is close to the nominal size, and also that applying GLS first does not lead to a size distortion. The tables show that when $x_{t}-x_{t-1}$ is linear $(\lambda=1)$, 
for a few series the log transformation introduces nonlinearity, although this increase is not very large. On the other hand, when $\ln \left(x_{t}\right)-\ln \left(x_{t-1}\right)$ is linear, quite some evidence for nonlinearity is found with increasing values of $\lambda$ (for both the OLS and GLS tests).

Our next set of experiments concern a nonlinear STAR model:

$$
y_{t}=1.8 y_{t-1}-1.06 y_{t-2}+\left(1+\exp \left(-\gamma\left(y_{t-1}-0.02\right)\right)\right)^{-1} *\left(\pi-0.9 y_{t-1}+0.795 y_{t-2}\right)+\epsilon_{t}
$$

where $\epsilon_{t} \sim N I D\left(0, .02^{2}\right)$. This DGP is also used in Teräsvirta (1994). We are free to choose different values for $\pi$ and $\gamma>0$. In this paper we choose the following parameter values for $(7)$ :

$$
\begin{array}{llll}
\text { Model 5: } & \lambda=1, \quad \gamma=100, & \pi=0.02 & x_{0}=10 \\
\text { Model 6: } & \lambda=1, \quad \gamma=100, & \pi=0 & x_{0}=25 \\
\text { Model 7: } & \lambda=1, \quad \gamma=20, & \pi=0.02 & x_{0}=10 \\
\text { Model 8: } & \lambda=1, \quad \gamma=20, & \pi=0 & x_{0}=25 \\
\text { Model 9: } & \lambda=0, \quad \gamma=100, & \pi=0.02 & x_{0}=0.01 \\
\text { Model 10: } & \lambda=0, \quad \gamma=100, & \pi=0 & x_{0}=100 \\
\text { Model 11: } & \lambda=0, \quad \gamma=20, & \pi=0.02 & x_{0}=0.1 \\
\text { Model 12: } & \lambda=0, \quad \gamma=20, & \pi=0 & x_{0}=100
\end{array}
$$

For models 5 and 6 the results are unambiguous: linearity is rejected 1000 out of 1000 times in all cases. Therefore, we did not make tables for these models. The results for models 7-12 can be found in Tables 12 - 17. Clearly, there are not many differences between the OLS-based and GLS-based test results. We can draw several conclusions from these results. First of all, and comparing the results of models 5,6,9,10 with models 7,8,11,12 we find that a smaller value of $\gamma$ yields less evidence of nonlinearity. This is likely to be due to the fact that the switching function in that case takes values closer to $\frac{1}{2}$, while when $\gamma=100$, the values of 1 and 0 are approached more frequently. Secondly, comparing the odd models with the even ones, we observe that frequently a $\pi$ value of 0.02 yields more evidence of nonlinearity, although the differences with $\pi=0$ are not very large. Thirdly, comparing models 5-8 with 9-12, we notice that if $x_{t}-x_{t-1}$ is nonlinear, one frequently finds that $x_{t}^{\lambda}-x_{t-1}^{\lambda}$ is also nonlinear, independent of the value of $\lambda$. Hence, it seems that in that case the Box-Cox transformation does not reduce evidence of nonlinearity. 
On the other hand, when $\ln \left(x_{t}\right)-\ln \left(x_{t-1}\right)$ is nonlinear, we observe that less evidence of nonlinearity is found with increasing values of $\lambda$.

For model 11 we find the U-shaped pattern, as was found for the monthly data in the former section, but for other models this pattern is not found. To investigate whether the lack of the U-Shape is perhaps due to our choice of $\lambda=0$ or $\lambda=1$ in the DGP, we repeat our exercise for the case when $\lambda=0.5$. We choose the following parameter values for $(7)$ :

$$
\begin{array}{lllll}
\text { Model 13: } & \lambda=0.5, & \gamma=20, & \pi=0 & x_{0}=16 \\
\text { Model 14: } & \lambda=0.5, & \gamma=20, & \pi=0.02 & x_{0}=16
\end{array}
$$

The results are presented in Tables 18 and 19, and we observe that the U-shape is also not encountered here. For $\pi=0$ the frequency of rejection decreases when $\lambda$ is increased. For $\pi=0.02$ this frequency is highest for the true value $\lambda=0.5$, and lowest around $\lambda=0$ and $\lambda=1$.

Finally, we address the question how the results from the simulation experiments shed light on the empirical findings in Tables 5, 6 and 7. Since the monthly series seem more informative, we choose to put more weight on the results in Table 5. The rejection frequencies in this table do not display a constant pattern across values of $\lambda$, and hence we may tentatively conclude that it seems best to consider the cases where $\lambda=0$ and for which the time series are either linear or nonlinear. Subject to the restriction that a time series is nonlinear for $\lambda=0$, we observe that the number of series where linearity is rejected decreases with increasing values of $\lambda$. Furthermore, subject to $\ln \left(x_{t}\right)-\ln \left(x_{t-1}\right)$ being linear, we observe an increase in evidence of nonlinearity with increasing values of $\lambda$. In sum, changing the Box-Cox parameter can lead to different conclusions regarding nonlinearity.

\section{Concluding remarks}

The empirical and simulation results in this paper seem to suggest that a useful starting point in practice is to take natural logs (and thus consider growth rates after first differencing). When evidence for nonlinearity (perhaps based on the value of LM test statistics) decreases (given nonlinearity of the growth rates) for other values of $\lambda$, one gains additional confidence in the necessity to use a nonlinear model for the growth rates. 
On the other hand, when such evidence increases if the growth rates appear linear, one may want to stick to a linear model. We also learned that studying nonlinearity is best done for disaggregated data and that quarterly data are perhaps less useful.

For the real-life monthly time series analyzed in this paper, we can conclude that many of these require a nonlinear model for description and forecasting, independent of the value of $\lambda$. This suggests that in practice one is still free to decide on the value of the Box-Cox parameter for a given time series at hand. Whether this decision influences key parameters in the subsequent nonlinear model and its out-of-sample point and interval forecast is a topic we aim to study in our further research. 
Table 1: Monthly data: Money.

\begin{tabular}{rlcc}
\hline \hline & \multicolumn{1}{c}{ Description } & & \\
Series & & Period & Length \\
\hline 1 & Commercial Paper Outstanding - All Issuers & $70.01-93.06$ & 282 \\
2 & Currency plus Demand Deposits & $59.01-97.09$ & 465 \\
3 & Currency Component of Money Stock Figure & $47.01-97.09$ & 609 \\
4 & Debt of Domestic Nonfinancial Sectors & $59.01-97.08$ & 464 \\
5 & Demand Deposits at Commercial Banks & $59.01-97.09$ & 465 \\
6 & Institutional Money Funds & $74.04-97.09$ & 282 \\
7 & Large Time Deposits at Commercial Banks & $59.01-97.09$ & 465 \\
8 & Large Time Deposits at Thrift Institutions & $70.02-97.09$ & 332 \\
9 & Liquid Assets & $59.01-97.08$ & 464 \\
10 & Large Time Deposits - Total & $59.01-97.09$ & 465 \\
11 & M1 Money Stock & $59.01-97.09$ & 465 \\
12 & M2 Money Stock & $59.01-97.09$ & 465 \\
13 & M3 Money Stock & $59.01-97.09$ & 465 \\
14 & Commerc. Paper Outstanding, Nonfinanc. Companies & $70.01-93.06$ & 282 \\
15 & Other Checkable Deposits & $63.01-97.09$ & 417 \\
16 & Retail Money Funds & $73.11-97.09$ & 287 \\
17 & Savings Deposits - Total & $59.01-97.09$ & 465 \\
18 & Small Time Deposits at Commercial Banks & $59.01-97.09$ & 465 \\
19 & Small Time Deposits - Total & $59.01-97.09$ & 465 \\
20 & Small Time Deposits at Thrift Institutions & $59.01-97.09$ & 465 \\
21 & Savings Deposits at Commercial Banks & $59.01-97.09$ & 465 \\
22 & Savings Deposits at Thrift Institutions & $59.01-97.09$ & 465 \\
23 & Savings and Small Time Deposits at Commercial Banks & $59.01-97.09$ & 465 \\
24 & Savings and Small Time Deposits - Total & $59.01-97.09$ & 465 \\
25 & Total Checkable Deposits & $59.01-97.09$ & 465 \\
26 & Total Time Deposits at Commercial Banks & $59.01-97.09$ & 465 \\
27 & Total Time Deposits at all Depository Inst. & $59.01-97.09$ & 465 \\
28 & Travelers' Checks Outstanding & $59.01-97.09$ & 465 \\
\hline
\end{tabular}


Table 2: Monthly data: Employment.

\begin{tabular}{rlcc}
\hline \hline & \multicolumn{1}{c}{ Description } & Period & Length \\
Series & & $64.01-97.10$ & 406 \\
1 & Aggreg. Weekly Hours Indx: Private Nonfarm Payrolls & $64.01-97.10$ & 406 \\
2 & Aver. Weekly Hours: Private Nonagricultural Establ. & $48.01-97.10$ & 598 \\
3 & Civilian Employment-16 years and older & $48.01-97.10$ & 598 \\
4 & Civilian Participation Rate & $48.01-97.10$ & 598 \\
5 & Civilian Labor Force & $48.01-97.10$ & 598 \\
6 & Employment Ratio & $51.01-97.09$ & 561 \\
7 & Index of Help Wanted Advertising in Newspapers & $46.01-97.10$ & 622 \\
8 & Manufacturing Employment & $46.01-97.10$ & 622 \\
9 & Payroll Employment of Wage and Salary Workers & $46.02-97.10$ & 621 \\
10 & Employment in Service Producing Industries & $48.01-97.10$ & 598 \\
11 & Civilian Unemployed for 15 Weeks and Over & $48.01-97.10$ & 598 \\
12 & Civilians Unemployed for Less Than 5 Weeks & $67.07-97.10$ & 364 \\
13 & Median Duration of Unemployment & $48.01-97.10$ & 598 \\
14 & Unemployed - All Civilian Workers & $48.01-97.10$ & 598 \\
15 & Unemployment Rate & $46.02-97.10$ & 621 \\
16 & Employment in Construction & $46.02-97.10$ & 621 \\
17 & Employment in Finance, Insurance, and Real Estate & $46.02-97.10$ & 621 \\
18 & Employment in Goods Producing Sectors & $46.02-97.10$ & 621 \\
19 & Employment in Government & $46.02-97.10$ & 621 \\
20 & Employment in Mining & $46.02-97.10$ & 621 \\
21 & Employment in Services & $46.02-97.10$ & 621 \\
22 & Employment in Transportation and Public Utilities & $46.02-97.10$ & 621 \\
23 & Employment in Retail Trade Industry & $46.02-97.10$ & 621 \\
24 & Employment in Wholesale Trade Industry & &
\end{tabular}

Table 3: Monthly data: Income and Expenditures.

\begin{tabular}{rlcc}
\hline \hline Series & \multicolumn{1}{c}{ Description } & Period & Length \\
\hline 1 & Disposable Personal Income & $59.01-97.09$ & 465 \\
2 & Real Disposable Personal Income & $59.01-97.09$ & 465 \\
3 & Personal Consumption Expenditures & $59.01-97.09$ & 465 \\
4 & Real Personal Consumption Expenditures & $59.01-97.09$ & 465 \\
5 & Pers. Cons. Expend.: Durable Goods & $59.01-97.09$ & 465 \\
6 & Real Pers. Cons. Expend.: Durable Goods & $59.01-97.09$ & 465 \\
7 & Pers. Cons. Expend.: Nondurable Goods & $59.01-97.09$ & 465 \\
8 & Real Pers. Cons. Expend.: Nondurable Goods & $59.01-97.09$ & 465 \\
9 & Pers. Cons. Expend.: Services & $59.01-97.09$ & 465 \\
10 & Real Pers. Cons. Expend.: Services & $59.01-97.09$ & 465 \\
11 & Personal Income & $46.01-97.09$ & 621 \\
12 & Personal Savings Rate & $59.01-97.09$ & 465 \\
\hline
\end{tabular}


Table 4: Quarterly data.

\begin{tabular}{|c|c|c|c|}
\hline Series & Description & Period & Length \\
\hline 1 & Final Sales to Domestic Purchasers & $59.1-97.3$ & 155 \\
\hline 2 & Real State \& Local Govn. Cons. Expend. \& Gross Invest. & $59.3-97.3$ & 153 \\
\hline 3 & Compensation of Employees & $59.1-97.3$ & 155 \\
\hline 4 & Consumption of Fixed Capital (GNP) & $59.1-97.3$ & 155 \\
\hline 5 & Corporate Profits After Tax with Iva \& CCAdj & $59.1-97.2$ & 154 \\
\hline 6 & Corporate Profits with IVA \& CCAdj & $59.1-97.2$ & 154 \\
\hline 7 & National Defense Gross Investment & $59.1-97.3$ & 155 \\
\hline 8 & Real National Defense Gross Investment & $59.3-97.3$ & 153 \\
\hline 9 & Disposable Personal Income & $59.1-97.3$ & 155 \\
\hline 10 & Real Disposable Personal Income & $59.3-97.3$ & 153 \\
\hline 11 & Exports of Goods And Services & $59.1-97.3$ & 155 \\
\hline 12 & Real Exports of Goods \& Services & $59.3-97.3$ & 153 \\
\hline 13 & Real Federal Cons. Expend. and Gross Invest. & $59.3-97.3$ & 153 \\
\hline 14 & Federal Government: Current Expenditures & $59.1-97.3$ & 155 \\
\hline 15 & Federal Government Receipts & $59.1-97.3$ & 155 \\
\hline 16 & Final Sales & $59.1-97.3$ & 155 \\
\hline 17 & Real Final Sales & $59.3-97.3$ & 153 \\
\hline 18 & Fixed Private Investment & $59.1-97.3$ & 155 \\
\hline 19 & Real Fixed Private Investment & $59.3-97.3$ & 153 \\
\hline 20 & Real Govn. Cons. Expend. and Gross Invest. & $59.3-97.3$ & 153 \\
\hline 21 & Gross Domestic Product & $59.1-97.3$ & 155 \\
\hline 22 & Real Gross Domestic Product Fixed & $59.1-97.3$ & 155 \\
\hline 23 & Real Gross Domestic Product Chained & $59.3-97.3$ & 153 \\
\hline 24 & Gross Domestic Product Chain-Type Price Index & $59.3-97.3$ & 153 \\
\hline 25 & Gross Domestic Product Implicit Price Deflator & $59.1-97.3$ & 155 \\
\hline 26 & Government Current Expenditures & $59.1-97.3$ & 155 \\
\hline 27 & Gross National Product & $59.3-97.3$ & 153 \\
\hline 28 & Real Gross National Product Fixed & $59.1-97.3$ & 155 \\
\hline 29 & Real Gross National Product Chained & $59.3-97.3$ & 153 \\
\hline 30 & Gross National Product Chain-Type Price Index & $59.3-97.3$ & 153 \\
\hline
\end{tabular}


Table 4: (continued).

\begin{tabular}{rlcc}
\hline \hline & \multicolumn{1}{c}{ Description } & Period & Length \\
Series & & $59.1-97.3$ & 155 \\
31 & Gross National Product Implicit Price Deflator & $59.1-97.3$ & 155 \\
32 & Gross Private Domestic Investment & $59.3-97.3$ & 153 \\
33 & Real Gross Private Domestic Investment & $59.3-97.3$ & 153 \\
34 & Gross Priv. Domestic Invest. Chain-Type Price Index & $59.1-97.3$ & 155 \\
35 & Gross Private Savings & $59.1-97.3$ & 155 \\
36 & Government Receipts & $59.1-97.3$ & 155 \\
37 & Gross Savings & $59.1-97.3$ & 155 \\
38 & Indirect Business Tax and Nontax Liability & $59.1-97.3$ & 155 \\
39 & Imports of Goods \& Services & $59.3-97.3$ & 153 \\
40 & Real Imports of Goods \& Services & $59.1-97.3$ & 155 \\
41 & Federal Nondefense Gross Investment & $59.3-97.3$ & 153 \\
42 & Real Federal Nondefense Gross Investment & $59.1-97.3$ & 155 \\
43 & State \& Local Government Current Expenditures & $59.1-97.3$ & 155 \\
44 & State \& Local Government Gross Investment & $59.3-97.3$ & 153 \\
45 & Real State \& Local Government Gross Investment & $59.1-97.3$ & 155 \\
46 & Nonfinancial Corporate Business Profits After Tax & $59.1-97.3$ & 155 \\
47 & National Income & $59.3-97.3$ & 153 \\
48 & Real Nonresidential Invest.: Producers' Durable Equip. & $59.3-97.3$ & 153 \\
49 & Personal Cons. Expend. Chain-Type Price Index & $59.3-97.3$ & 153 \\
50 & Real Private Nonresidential Fixed Investment & $59.3-97.3$ & 153 \\
51 & Real Private Residential Fixed Investment & $59.1-97.3$ & 155 \\
52 & Proprietors Income with IVA \& CCAdj & $59.1-97.3$ & 155 \\
53 & Personal Saving &
\end{tabular}


Table 5: Monthly data: number of series (out of the 64) for which linearity is rejected

\begin{tabular}{|c|c|c|c|c|c|c|c|c|c|c|c|c|c|c|c|c|}
\hline \multirow{3}{*}{$\frac{\lambda}{0}$} & \multicolumn{8}{|c|}{ OLS } & \multicolumn{8}{|c|}{ GLS } \\
\hline & \multicolumn{2}{|c|}{ AIC95 } & \multicolumn{2}{|c|}{ AIC90 } & \multicolumn{2}{|c|}{ BIC95 } & \multicolumn{2}{|c|}{ BIC90 } & \multicolumn{2}{|c|}{ AIC95 } & \multicolumn{2}{|c|}{ AIC90 } & \multicolumn{2}{|c|}{ BIC95 } & \multicolumn{2}{|c|}{ BIC90 } \\
\hline & 48 & 48 & 53 & 53 & 46 & 46 & 52 & 52 & 48 & 48 & 51 & 51 & 42 & 42 & 47 & 47 \\
\hline 0.05 & 50 & 48 & 54 & 52 & 47 & 45 & 52 & 51 & 47 & 47 & 51 & 51 & 42 & 42 & 47 & 47 \\
\hline 0.10 & 50 & 47 & 55 & 52 & 48 & 45 & 53 & 51 & 46 & 46 & 51 & 51 & 42 & 42 & 47 & 47 \\
\hline 0.15 & 50 & 46 & 55 & 52 & 45 & 41 & 51 & 49 & 46 & 46 & 51 & 51 & 42 & 42 & 47 & 47 \\
\hline 0.20 & 51 & 46 & 54 & 51 & 44 & 41 & 49 & 47 & 45 & 45 & 49 & 49 & 40 & 40 & 46 & 46 \\
\hline 0.25 & 51 & 46 & 54 & 51 & 43 & 40 & 49 & 47 & 45 & 44 & 49 & 49 & 39 & 38 & 46 & 46 \\
\hline 0.30 & 51 & 46 & 54 & 51 & 42 & 38 & 47 & 45 & 45 & 44 & 50 & 49 & 39 & 38 & 48 & 47 \\
\hline 0.35 & 50 & 44 & 54 & 50 & 40 & 35 & 49 & 45 & 45 & 44 & 50 & 49 & 39 & 38 & 47 & 46 \\
\hline 0.40 & 47 & 41 & 53 & 48 & 39 & 34 & 45 & 41 & 46 & 44 & 50 & 49 & 39 & 37 & 45 & 44 \\
\hline 0.45 & 47 & 40 & 51 & 47 & 42 & 36 & 46 & 42 & 47 & 45 & 50 & 48 & 40 & 37 & 46 & 43 \\
\hline 0.50 & 47 & 40 & 51 & 46 & 41 & 36 & 48 & 43 & 46 & 44 & 50 & 48 & 40 & 37 & 46 & 43 \\
\hline 0.55 & 46 & 39 & 52 & 47 & 41 & 36 & 49 & 43 & 46 & 44 & 51 & 48 & 40 & 37 & 46 & 42 \\
\hline 0.60 & 47 & 38 & 51 & 46 & 43 & 36 & 47 & 42 & 46 & 44 & 51 & 48 & 38 & 36 & 46 & 42 \\
\hline 0.65 & 48 & 39 & 51 & 46 & 43 & 36 & 47 & 42 & 46 & 43 & 49 & 47 & 39 & 36 & 45 & 42 \\
\hline 0.70 & 48 & 39 & 51 & 46 & 44 & 35 & 47 & 42 & 46 & 43 & 50 & 47 & 39 & 36 & 44 & 41 \\
\hline 0.75 & 48 & 39 & 51 & 45 & 45 & 36 & 48 & 42 & 46 & 43 & 50 & 47 & 40 & 36 & 45 & 41 \\
\hline 0.80 & 49 & 39 & 51 & 45 & 46 & 36 & 48 & 42 & 45 & 43 & 49 & 46 & 39 & 36 & 45 & 41 \\
\hline 0.85 & 49 & 39 & 52 & 46 & 46 & 36 & 48 & 42 & 45 & 43 & 48 & 46 & 40 & 36 & 44 & 41 \\
\hline 0.90 & 49 & 39 & 52 & 46 & 47 & 37 & 49 & 43 & 44 & 42 & 49 & 46 & 40 & 37 & 45 & 42 \\
\hline 0.95 & 49 & 38 & 52 & 46 & 47 & 37 & 49 & 43 & 43 & 41 & 48 & 45 & 39 & 37 & 44 & 42 \\
\hline 1.00 & 50 & 39 & 54 & 47 & 48 & 38 & 51 & 44 & 44 & 41 & 48 & 45 & 40 & 37 & 45 & 43 \\
\hline
\end{tabular}


Table 6: monthly data aggregated to quarterly: number of series (out of the 64) for which linearity is rejected

\begin{tabular}{|c|c|c|c|c|c|c|c|c|c|c|c|c|c|c|c|c|}
\hline \multirow[b]{2}{*}{$\lambda$} & \multicolumn{8}{|c|}{ OLS } & \multicolumn{8}{|c|}{ GLS } \\
\hline & $\overline{\mathrm{AIC}}$ & 95 & $\mathrm{AI}$ & 90 & & 95 & & 90 & $\overline{\mathrm{AIC}}$ & 95 & $\overline{\mathrm{AI}}$ & 90 & $\overline{B I}$ & 95 & $\overline{\mathrm{BI}}$ & 90 \\
\hline 0 & 27 & 27 & 30 & 30 & 22 & 22 & 25 & 25 & 21 & 21 & 26 & 26 & 18 & 18 & 20 & 20 \\
\hline 0.05 & 25 & 25 & 29 & 29 & 18 & 18 & 21 & 21 & 20 & 19 & 26 & 24 & 16 & 16 & 22 & 20 \\
\hline 0.10 & 25 & 23 & 28 & 25 & 18 & 17 & 20 & 19 & 20 & 19 & 26 & 24 & 16 & 16 & 24 & 20 \\
\hline 0.15 & 24 & 22 & 27 & 23 & 18 & 17 & 20 & 19 & 22 & 20 & 26 & 24 & 19 & 18 & 22 & 20 \\
\hline 0.20 & 24 & 23 & 28 & 24 & 19 & 18 & 21 & 19 & 23 & 19 & 26 & 23 & 20 & 18 & 23 & 20 \\
\hline 0.25 & 25 & 23 & 28 & 24 & 19 & 18 & 21 & 19 & 25 & 20 & 31 & 24 & 20 & 18 & 24 & 20 \\
\hline 0.30 & 25 & 23 & 29 & 26 & 21 & 19 & 24 & 21 & 23 & 19 & 29 & 23 & 20 & 18 & 24 & 20 \\
\hline 0.35 & 26 & 24 & 28 & 25 & 23 & 20 & 25 & 21 & 22 & 18 & 28 & 23 & 19 & 17 & 23 & 20 \\
\hline 0.40 & 26 & 24 & 29 & 25 & 23 & 20 & 26 & 21 & 24 & 19 & 28 & 23 & 20 & 18 & 24 & 20 \\
\hline 0.45 & 26 & 24 & 31 & 25 & 23 & 20 & 27 & 21 & 24 & 19 & 29 & 24 & 20 & 18 & 25 & 20 \\
\hline 0.50 & 26 & 23 & 30 & 24 & 22 & 18 & 25 & 19 & 24 & 19 & 29 & 24 & 22 & 18 & 25 & 20 \\
\hline 0.55 & 27 & 23 & 32 & 25 & 22 & 18 & 25 & 19 & 23 & 18 & 28 & 24 & 21 & 17 & 25 & 20 \\
\hline 0.60 & 27 & 23 & 33 & 25 & 22 & 18 & 26 & 19 & 23 & 18 & 28 & 24 & 21 & 17 & 25 & 20 \\
\hline 0.65 & 27 & 22 & 34 & 25 & 22 & 17 & 27 & 19 & 22 & 18 & 29 & 24 & 22 & 17 & 26 & 20 \\
\hline 0.70 & 29 & 22 & 32 & 24 & 23 & 17 & 26 & 18 & 24 & 18 & 29 & 24 & 22 & 17 & 26 & 20 \\
\hline 0.75 & 29 & 22 & 32 & 24 & 23 & 17 & 25 & 17 & 23 & 18 & 30 & 24 & 22 & 17 & 26 & 20 \\
\hline 0.80 & 29 & 21 & 32 & 24 & 25 & 17 & 27 & 18 & 24 & 19 & 30 & 24 & 23 & 18 & 26 & 20 \\
\hline 0.85 & 29 & 21 & 33 & 23 & 25 & 17 & 29 & 19 & 24 & 19 & 30 & 24 & 23 & 18 & 26 & 20 \\
\hline 0.90 & 30 & 21 & 33 & 23 & 27 & 16 & 30 & 19 & 24 & 20 & 29 & 25 & 22 & 18 & 25 & 20 \\
\hline 0.95 & 30 & 21 & 34 & 22 & 28 & 16 & 32 & 19 & 25 & 20 & 31 & 25 & 22 & 18 & 27 & 20 \\
\hline 1.00 & 30 & 20 & 36 & 22 & 29 & 17 & 33 & 19 & 25 & 20 & 31 & 24 & 22 & 18 & 28 & 20 \\
\hline
\end{tabular}


Table 7: Quarterly data: number of series (out of the 53) for which linearity is rejected

\begin{tabular}{|c|c|c|c|c|c|c|c|c|c|c|c|c|c|c|c|c|}
\hline \multirow{3}{*}{$\frac{\lambda}{0}$} & \multicolumn{8}{|c|}{ OLS } & \multicolumn{8}{|c|}{ GLS } \\
\hline & \multicolumn{2}{|c|}{ AIC95 } & \multicolumn{2}{|c|}{ AIC90 } & \multicolumn{2}{|c|}{ BIC95 } & \multicolumn{2}{|c|}{ BIC90 } & \multicolumn{2}{|c|}{ AIC95 } & \multicolumn{2}{|c|}{ AIC90 } & \multicolumn{2}{|c|}{ BIC95 } & \multicolumn{2}{|c|}{ BIC90 } \\
\hline & 16 & 16 & 18 & 18 & 9 & 9 & 13 & 13 & 17 & 17 & 19 & 19 & 11 & 11 & 13 & 13 \\
\hline 0.05 & 15 & 15 & 18 & 18 & 9 & 9 & 14 & 13 & 16 & 16 & 18 & 17 & 10 & 10 & 13 & 12 \\
\hline 0.10 & 13 & 13 & 16 & 16 & 10 & 9 & 14 & 12 & 17 & 16 & 21 & 18 & 10 & 10 & 13 & 12 \\
\hline 0.15 & 12 & 12 & 17 & 16 & 10 & 9 & 16 & 12 & 16 & 16 & 20 & 18 & 10 & 10 & 13 & 12 \\
\hline 0.20 & 13 & 11 & 18 & 15 & 11 & 9 & 16 & 12 & 14 & 14 & 18 & 15 & 10 & 10 & 14 & 12 \\
\hline 0.25 & 15 & 11 & 19 & 15 & 11 & 8 & 16 & 12 & 14 & 14 & 19 & 15 & 10 & 10 & 14 & 12 \\
\hline 0.30 & 15 & 9 & 21 & 15 & 12 & 7 & 16 & 11 & 14 & 14 & 18 & 14 & 10 & 10 & 12 & 10 \\
\hline 0.35 & 14 & 7 & 19 & 13 & 11 & 5 & 16 & 11 & 14 & 14 & 18 & 14 & 10 & 10 & 12 & 10 \\
\hline 0.40 & 15 & 7 & 19 & 12 & 12 & 5 & 18 & 10 & 14 & 12 & 20 & 14 & 8 & 7 & 12 & 10 \\
\hline 0.45 & 17 & 7 & 22 & 13 & 13 & 4 & 18 & 10 & 13 & 12 & 19 & 14 & 9 & 7 & 13 & 9 \\
\hline 0.50 & 18 & 8 & 22 & 13 & 13 & 4 & 19 & 10 & 13 & 12 & 19 & 14 & 9 & 7 & 13 & 9 \\
\hline 0.55 & 18 & 7 & 21 & 12 & 15 & 4 & 20 & 10 & 14 & 12 & 19 & 14 & 9 & 7 & 13 & 9 \\
\hline 0.60 & 18 & 7 & 21 & 12 & 15 & 4 & 21 & 9 & 14 & 12 & 18 & 13 & 10 & 8 & 13 & 9 \\
\hline 0.65 & 20 & 7 & 24 & 12 & 15 & 4 & 21 & 9 & 16 & 12 & 18 & 13 & 11 & 8 & 13 & 9 \\
\hline 0.70 & 22 & 8 & 24 & 11 & 18 & 5 & 21 & 8 & 17 & 11 & 19 & 13 & 12 & 7 & 13 & 9 \\
\hline 0.75 & 21 & 7 & 22 & 10 & 18 & 5 & 21 & 8 & 18 & 11 & 19 & 13 & 12 & 7 & 12 & 8 \\
\hline 0.80 & 20 & 6 & 21 & 9 & 18 & 4 & 22 & 8 & 18 & 11 & 19 & 13 & 12 & 7 & 12 & 8 \\
\hline 0.85 & 20 & 6 & 22 & 10 & 19 & 4 & 22 & 8 & 18 & 11 & 19 & 13 & 11 & 6 & 12 & 8 \\
\hline 0.90 & 19 & 6 & 23 & 10 & 18 & 4 & 23 & 8 & 20 & 12 & 22 & 14 & 12 & 7 & 13 & 9 \\
\hline 0.95 & 20 & 6 & 23 & 9 & 18 & 4 & 24 & 8 & 18 & 10 & 23 & 14 & 10 & 5 & 14 & 9 \\
\hline 1.00 & 20 & 7 & 23 & 10 & 16 & 4 & 21 & 7 & 16 & 8 & 23 & 13 & 10 & 5 & 14 & 9 \\
\hline
\end{tabular}


Table 8: Number of series (out of 1000) for which linearity is rejected, Model 1

\begin{tabular}{|c|c|c|c|c|c|c|c|c|}
\hline \multirow[b]{2}{*}{$\lambda$} & \multicolumn{4}{|c|}{ OLS } & \multicolumn{4}{|c|}{ GLS } \\
\hline & AIC95 & $\overline{\text { AIC90 }}$ & $\overline{\text { BIC95 }}$ & $\overline{\text { BIC90 }}$ & AIC95 & AIC90 & $\overline{\text { BIC95 }}$ & $\overline{\text { BIC90 }}$ \\
\hline 0 & 55 & 123 & 56 & 121 & 52 & 107 & 53 & 95 \\
\hline 0.05 & 55 & 123 & 56 & 120 & 50 & 105 & 52 & 94 \\
\hline 0.10 & 54 & 122 & 55 & 119 & 51 & 104 & 52 & 94 \\
\hline 0.15 & 54 & 123 & 55 & 120 & 51 & 103 & 51 & 94 \\
\hline 0.20 & 54 & 122 & 55 & 120 & 50 & 103 & 48 & 94 \\
\hline 0.25 & 54 & 121 & 55 & 119 & 50 & 103 & 48 & 93 \\
\hline 0.30 & 54 & 121 & 55 & 119 & 49 & 100 & 47 & 90 \\
\hline 0.35 & 54 & 121 & 55 & 117 & 50 & 101 & 47 & 91 \\
\hline 0.40 & 54 & 121 & 55 & 117 & 50 & 101 & 47 & 92 \\
\hline 0.45 & 54 & 122 & 55 & 118 & 49 & 99 & 47 & 92 \\
\hline 0.50 & 52 & 121 & 53 & 117 & 49 & 98 & 47 & 92 \\
\hline 0.55 & 51 & 118 & 52 & 114 & 49 & 98 & 47 & 92 \\
\hline 0.60 & 51 & 117 & 51 & 113 & 50 & 100 & 46 & 94 \\
\hline 0.65 & 51 & 116 & 51 & 112 & 50 & 100 & 46 & 95 \\
\hline 0.70 & 51 & 119 & 51 & 114 & 50 & 100 & 46 & 94 \\
\hline 0.75 & 51 & 118 & 51 & 113 & 50 & 102 & 46 & 95 \\
\hline 0.80 & 51 & 118 & 51 & 113 & 50 & 102 & 46 & 95 \\
\hline 0.85 & 51 & 115 & 50 & 110 & 50 & 105 & 46 & 97 \\
\hline 0.90 & 51 & 115 & 50 & 110 & 49 & 105 & 45 & 97 \\
\hline 0.95 & 50 & 114 & 49 & 109 & 49 & 103 & 45 & 96 \\
\hline 1.00 & 49 & 115 & 48 & 107 & 49 & 104 & 45 & 97 \\
\hline
\end{tabular}


Table 9: Number of series (out of 1000) for which linearity is rejected, Model 2

\begin{tabular}{|c|c|c|c|c|c|c|c|c|}
\hline \multirow[b]{2}{*}{$\lambda$} & \multicolumn{4}{|c|}{ OLS } & \multicolumn{4}{|c|}{ GLS } \\
\hline & AIC95 & AIC90 & $\overline{\text { BIC95 }}$ & $\overline{\text { BIC90 }}$ & AIC95 & $\overline{\mathrm{AIC}} 90$ & $\overline{\text { BIC95 }}$ & $\overline{\text { BIC90 }}$ \\
\hline 0 & 110 & 187 & 111 & 188 & 63 & 122 & 71 & 128 \\
\hline 0.05 & 105 & 175 & 106 & 179 & 61 & 118 & 70 & 124 \\
\hline 0.10 & 94 & 163 & 96 & 168 & 59 & 119 & 67 & 123 \\
\hline 0.15 & 86 & 159 & 88 & 158 & 58 & 119 & 65 & 124 \\
\hline 0.20 & 81 & 153 & 83 & 151 & 62 & 131 & 66 & 133 \\
\hline 0.25 & 76 & 145 & 78 & 142 & 64 & 125 & 67 & 127 \\
\hline 0.30 & 73 & 134 & 75 & 136 & 64 & 128 & 67 & 129 \\
\hline 0.35 & 70 & 126 & 75 & 129 & 65 & 125 & 68 & 126 \\
\hline 0.40 & 70 & 121 & 73 & 124 & 63 & 130 & 68 & 131 \\
\hline 0.45 & 69 & 117 & 74 & 120 & 63 & 127 & 66 & 129 \\
\hline 0.50 & 66 & 109 & 73 & 114 & 64 & 122 & 66 & 121 \\
\hline 0.55 & 65 & 103 & 74 & 107 & 60 & 126 & 63 & 127 \\
\hline 0.60 & 64 & 101 & 71 & 106 & 57 & 127 & 62 & 128 \\
\hline 0.65 & 62 & 101 & 67 & 107 & 63 & 129 & 66 & 128 \\
\hline 0.70 & 60 & 103 & 66 & 108 & 63 & 128 & 66 & 129 \\
\hline 0.75 & 61 & 108 & 66 & 111 & 60 & 126 & 63 & 129 \\
\hline 0.80 & 57 & 107 & 62 & 109 & 63 & 124 & 64 & 128 \\
\hline 0.85 & 57 & 109 & 62 & 110 & 68 & 122 & 69 & 125 \\
\hline 0.90 & 57 & 110 & 63 & 112 & 62 & 124 & 63 & 125 \\
\hline 0.95 & 56 & 115 & 63 & 116 & 63 & 122 & 65 & 123 \\
\hline 1.00 & 56 & 111 & 63 & 114 & 61 & 123 & 65 & 124 \\
\hline
\end{tabular}


Table 10: Number of series (out of 1000) for which linearity is rejected, Model 3

\begin{tabular}{|c|c|c|c|c|c|c|c|c|}
\hline \multirow[b]{2}{*}{$\lambda$} & \multicolumn{4}{|c|}{ OLS } & \multicolumn{4}{|c|}{ GLS } \\
\hline & AIC95 & $\overline{\text { AIC90 }}$ & $\overline{\mathrm{BIC} 95}$ & $\overline{\text { BIC90 }}$ & AIC95 & AIC90 & $\overline{\text { BIC95 }}$ & $\overline{\text { BIC90 }}$ \\
\hline 0 & 60 & 119 & 54 & 115 & 59 & 109 & 59 & 111 \\
\hline 0.05 & 63 & 123 & 56 & 117 & 60 & 108 & 59 & 109 \\
\hline 0.10 & 64 & 122 & 57 & 113 & 61 & 112 & 59 & 117 \\
\hline 0.15 & 62 & 118 & 59 & 112 & 61 & 116 & 59 & 118 \\
\hline 0.20 & 69 & 126 & 67 & 121 & 61 & 128 & 63 & 129 \\
\hline 0.25 & 76 & 138 & 74 & 131 & 63 & 138 & 67 & 138 \\
\hline 0.30 & 81 & 140 & 79 & 134 & 75 & 146 & 76 & 143 \\
\hline 0.35 & 92 & 151 & 92 & 146 & 89 & 151 & 89 & 153 \\
\hline 0.40 & 100 & 159 & 99 & 154 & 94 & 163 & 94 & 167 \\
\hline 0.45 & 107 & 177 & 108 & 170 & 101 & 177 & 105 & 183 \\
\hline 0.50 & 123 & 191 & 120 & 188 & 110 & 198 & 119 & 207 \\
\hline 0.55 & 135 & 208 & 136 & 208 & 127 & 215 & 136 & 218 \\
\hline 0.60 & 147 & 234 & 151 & 235 & 145 & 234 & 155 & 240 \\
\hline 0.65 & 168 & 257 & 173 & 264 & 161 & 256 & 169 & 264 \\
\hline 0.70 & 186 & 279 & 190 & 288 & 178 & 286 & 190 & 297 \\
\hline 0.75 & 204 & 299 & 208 & 313 & 201 & 318 & 213 & 335 \\
\hline 0.80 & 227 & 326 & 237 & 337 & 221 & 341 & 233 & 361 \\
\hline 0.85 & 245 & 354 & 260 & 364 & 246 & 368 & 262 & 384 \\
\hline 0.90 & 271 & 395 & 292 & 404 & 274 & 389 & 288 & 407 \\
\hline 0.95 & 297 & 425 & 318 & 434 & 309 & 415 & 328 & 430 \\
\hline 1.00 & 338 & 452 & 353 & 469 & 339 & 444 & 360 & 463 \\
\hline
\end{tabular}


Table 11: Number of series (out of 1000) for which linearity is rejected, Model 4

\begin{tabular}{|c|c|c|c|c|c|c|c|c|}
\hline \multirow[b]{2}{*}{$\lambda$} & \multicolumn{4}{|c|}{ OLS } & \multicolumn{4}{|c|}{ GLS } \\
\hline & AIC95 & AIC90 & BIC95 & BIC90 & AIC95 & $\overline{\mathrm{AIC}} 90$ & $\overline{B I C 95}$ & $\overline{\text { BIC90 }}$ \\
\hline 0 & 63 & 107 & 59 & 104 & 56 & 116 & 55 & 115 \\
\hline 0.05 & 74 & 139 & 70 & 130 & 58 & 113 & 58 & 111 \\
\hline 0.10 & 177 & 281 & 172 & 266 & 62 & 118 & 64 & 117 \\
\hline 0.15 & 398 & 515 & 394 & 511 & 64 & 124 & 61 & 121 \\
\hline 0.20 & 645 & 756 & 639 & 741 & 62 & 130 & 62 & 136 \\
\hline 0.25 & 821 & 882 & 798 & 864 & 84 & 156 & 87 & 162 \\
\hline 0.30 & 911 & 955 & 901 & 945 & 122 & 204 & 114 & 201 \\
\hline 0.35 & 950 & 977 & 941 & 971 & 206 & 306 & 203 & 299 \\
\hline 0.40 & 974 & 987 & 973 & 985 & 327 & 433 & 330 & 419 \\
\hline 0.45 & 980 & 992 & 979 & 991 & 493 & 610 & 478 & 585 \\
\hline 0.50 & 985 & 995 & 984 & 995 & 673 & 755 & 635 & 733 \\
\hline 0.55 & 990 & 996 & 990 & 996 & 803 & 854 & 787 & 847 \\
\hline 0.60 & 989 & 997 & 989 & 996 & 879 & 912 & 869 & 905 \\
\hline 0.65 & 993 & 998 & 990 & 997 & 925 & 955 & 915 & 943 \\
\hline 0.70 & 993 & 997 & 989 & 996 & 952 & 970 & 941 & 959 \\
\hline 0.75 & 993 & 997 & 989 & 994 & 970 & 976 & 958 & 968 \\
\hline 0.80 & 995 & 999 & 991 & 996 & 972 & 982 & 964 & 977 \\
\hline 0.85 & 995 & 999 & 992 & 996 & 974 & 988 & 969 & 983 \\
\hline 0.90 & 996 & 999 & 992 & 996 & 983 & 991 & 978 & 987 \\
\hline 0.95 & 996 & 999 & 993 & 997 & 986 & 993 & 983 & 990 \\
\hline 1.00 & 996 & 999 & 993 & 997 & 991 & 994 & 987 & 993 \\
\hline
\end{tabular}


Table 12: Number of series (out of 1000) for which linearity is rejected, Model 7

\begin{tabular}{|c|c|c|c|c|c|c|c|c|}
\hline \multirow[b]{2}{*}{$\lambda$} & \multicolumn{4}{|c|}{ OLS } & \multicolumn{4}{|c|}{ GLS } \\
\hline & AIC95 & AIC90 & BIC95 & $\overline{\text { BIC90 }}$ & AIC95 & AIC90 & $\overline{\text { BIC95 }}$ & $\overline{\text { BIC90 }}$ \\
\hline 0 & 899 & 937 & 910 & 943 & 933 & 970 & 953 & 976 \\
\hline 0.05 & 900 & 937 & 912 & 944 & 931 & 968 & 952 & 975 \\
\hline 0.10 & 901 & 940 & 914 & 947 & 930 & 968 & 951 & 976 \\
\hline 0.15 & 901 & 938 & 915 & 946 & 930 & 965 & 951 & 976 \\
\hline 0.20 & 901 & 937 & 917 & 948 & 930 & 966 & 950 & 975 \\
\hline 0.25 & 901 & 939 & 916 & 949 & 932 & 967 & 952 & 975 \\
\hline 0.30 & 904 & 940 & 918 & 949 & 933 & 964 & 953 & 973 \\
\hline 0.35 & 905 & 942 & 918 & 951 & 933 & 964 & 953 & 973 \\
\hline 0.40 & 904 & 943 & 920 & 955 & 932 & 963 & 951 & 972 \\
\hline 0.45 & 905 & 943 & 922 & 957 & 931 & 963 & 949 & 973 \\
\hline 0.50 & 906 & 944 & 924 & 958 & 929 & 964 & 948 & 973 \\
\hline 0.55 & 910 & 948 & 926 & 959 & 927 & 965 & 946 & 974 \\
\hline 0.60 & 911 & 947 & 926 & 958 & 928 & 964 & 947 & 973 \\
\hline 0.65 & 914 & 948 & 929 & 959 & 926 & 966 & 945 & 974 \\
\hline 0.70 & 916 & 949 & 931 & 961 & 927 & 966 & 945 & 975 \\
\hline 0.75 & 919 & 948 & 935 & 960 & 926 & 968 & 944 & 976 \\
\hline 0.80 & 922 & 952 & 938 & 961 & 926 & 968 & 945 & 977 \\
\hline 0.85 & 922 & 954 & 938 & 962 & 927 & 966 & 945 & 977 \\
\hline 0.90 & 923 & 955 & 938 & 963 & 926 & 965 & 945 & 976 \\
\hline 0.95 & 922 & 956 & 937 & 963 & 926 & 965 & 945 & 975 \\
\hline 1.00 & 922 & 956 & 938 & 962 & 925 & 965 & 943 & 977 \\
\hline
\end{tabular}


Table 13: Number of series (out of 1000) for which linearity is rejected, Model 8

\begin{tabular}{|c|c|c|c|c|c|c|c|c|}
\hline \multirow[b]{2}{*}{$\lambda$} & \multicolumn{4}{|c|}{ OLS } & \multicolumn{4}{|c|}{ GLS } \\
\hline & AIC95 & AIC90 & $\overline{\text { BIC95 }}$ & BIC90 & AIC95 & $\overline{\mathrm{AIC}} 90$ & $\overline{\text { BIC95 }}$ & $\overline{\text { BIC90 }}$ \\
\hline 0 & 987 & 991 & 991 & 996 & 982 & 989 & 983 & 989 \\
\hline 0.05 & 987 & 992 & 991 & 996 & 982 & 989 & 983 & 989 \\
\hline 0.10 & 987 & 992 & 991 & 996 & 980 & 989 & 983 & 989 \\
\hline 0.15 & 987 & 992 & 991 & 996 & 980 & 989 & 983 & 989 \\
\hline 0.20 & 987 & 992 & 991 & 996 & 979 & 988 & 982 & 989 \\
\hline 0.25 & 987 & 992 & 991 & 996 & 979 & 988 & 981 & 989 \\
\hline 0.30 & 987 & 992 & 991 & 996 & 979 & 987 & 981 & 988 \\
\hline 0.35 & 987 & 992 & 991 & 996 & 979 & 986 & 981 & 988 \\
\hline 0.40 & 987 & 992 & 991 & 996 & 979 & 987 & 981 & 987 \\
\hline 0.45 & 987 & 992 & 991 & 996 & 979 & 987 & 981 & 987 \\
\hline 0.50 & 987 & 992 & 991 & 996 & 978 & 987 & 980 & 987 \\
\hline 0.55 & 987 & 992 & 991 & 996 & 978 & 987 & 980 & 987 \\
\hline 0.60 & 987 & 992 & 991 & 996 & 978 & 987 & 980 & 987 \\
\hline 0.65 & 987 & 992 & 991 & 996 & 978 & 987 & 980 & 987 \\
\hline 0.70 & 987 & 992 & 991 & 996 & 978 & 987 & 980 & 987 \\
\hline 0.75 & 987 & 992 & 991 & 996 & 978 & 987 & 980 & 987 \\
\hline 0.80 & 987 & 992 & 991 & 996 & 978 & 987 & 979 & 987 \\
\hline 0.85 & 987 & 992 & 991 & 996 & 978 & 987 & 979 & 987 \\
\hline 0.90 & 987 & 992 & 991 & 996 & 978 & 987 & 979 & 987 \\
\hline 0.95 & 985 & 991 & 991 & 995 & 978 & 987 & 979 & 987 \\
\hline 1.00 & 984 & 991 & 990 & 995 & 978 & 987 & 979 & 987 \\
\hline
\end{tabular}


Table 14: Number of series (out of 1000) for which linearity is rejected, Model 9

\begin{tabular}{|c|c|c|c|c|c|c|c|c|}
\hline \multirow[b]{2}{*}{$\lambda$} & \multicolumn{4}{|c|}{ OLS } & \multicolumn{4}{|c|}{ GLS } \\
\hline & AIC95 & AIC90 & BIC95 & $\overline{\text { BIC90 }}$ & AIC95 & AIC90 & $\overline{\text { BIC95 }}$ & $\overline{\mathrm{BIC} 90}$ \\
\hline 0 & 1000 & 1000 & 1000 & 1000 & 1000 & 1000 & 1000 & 1000 \\
\hline 0.05 & 1000 & 1000 & 1000 & 1000 & 1000 & 1000 & 1000 & 1000 \\
\hline 0.10 & 1000 & 1000 & 1000 & 1000 & 1000 & 1000 & 1000 & 1000 \\
\hline 0.15 & 1000 & 1000 & 1000 & 1000 & 1000 & 1000 & 1000 & 1000 \\
\hline 0.20 & 997 & 997 & 997 & 998 & 1000 & 1000 & 1000 & 1000 \\
\hline 0.25 & 993 & 995 & 990 & 994 & 1000 & 1000 & 1000 & 1000 \\
\hline 0.30 & 989 & 994 & 985 & 990 & 999 & 1000 & 999 & 1000 \\
\hline 0.35 & 986 & 993 & 984 & 992 & 998 & 999 & 998 & 999 \\
\hline 0.40 & 984 & 989 & 982 & 987 & 996 & 999 & 996 & 998 \\
\hline 0.45 & 982 & 987 & 977 & 983 & 994 & 998 & 992 & 996 \\
\hline 0.50 & 979 & 984 & 974 & 982 & 990 & 996 & 986 & 994 \\
\hline 0.55 & 973 & 982 & 966 & 975 & 987 & 993 & 985 & 990 \\
\hline 0.60 & 975 & 983 & 963 & 976 & 983 & 991 & 981 & 990 \\
\hline 0.65 & 972 & 982 & 956 & 971 & 970 & 982 & 971 & 984 \\
\hline 0.70 & 972 & 981 & 953 & 964 & 960 & 977 & 959 & 976 \\
\hline 0.75 & 973 & 982 & 952 & 966 & 957 & 970 & 955 & 966 \\
\hline 0.80 & 967 & 979 & 941 & 962 & 951 & 968 & 944 & 961 \\
\hline 0.85 & 962 & 973 & 939 & 958 & 944 & 968 & 930 & 955 \\
\hline 0.90 & 958 & 970 & 932 & 949 & 944 & 965 & 920 & 951 \\
\hline 0.95 & 957 & 968 & 928 & 943 & 936 & 964 & 916 & 948 \\
\hline 1.00 & 957 & 968 & 929 & 943 & 939 & 964 & 919 & 947 \\
\hline
\end{tabular}


Table 15: Number of series (out of 1000) for which linearity is rejected, Model 10

\begin{tabular}{|c|c|c|c|c|c|c|c|c|}
\hline \multirow[b]{2}{*}{$\lambda$} & \multicolumn{4}{|c|}{ OLS } & \multicolumn{4}{|c|}{ GLS } \\
\hline & AIC95 & AIC90 & BIC95 & BIC90 & AIC95 & AIC90 & $\overline{\text { BIC95 }}$ & $\overline{\text { BIC90 }}$ \\
\hline 0 & 1000 & 1000 & 1000 & 1000 & 1000 & 1000 & 1000 & 1000 \\
\hline 0.05 & 1000 & 1000 & 1000 & 1000 & 1000 & 1000 & 1000 & 1000 \\
\hline 0.10 & 1000 & 1000 & 1000 & 1000 & 1000 & 1000 & 1000 & 1000 \\
\hline 0.15 & 1000 & 1000 & 1000 & 1000 & 1000 & 1000 & 1000 & 1000 \\
\hline 0.20 & 1000 & 1000 & 1000 & 1000 & 1000 & 1000 & 1000 & 1000 \\
\hline 0.25 & 1000 & 1000 & 1000 & 1000 & 1000 & 1000 & 1000 & 1000 \\
\hline 0.30 & 1000 & 1000 & 1000 & 1000 & 1000 & 1000 & 1000 & 1000 \\
\hline 0.35 & 1000 & 1000 & 1000 & 1000 & 1000 & 1000 & 1000 & 1000 \\
\hline 0.40 & 1000 & 1000 & 1000 & 1000 & 1000 & 1000 & 1000 & 1000 \\
\hline 0.45 & 1000 & 1000 & 999 & 1000 & 999 & 1000 & 1000 & 1000 \\
\hline 0.50 & 999 & 1000 & 999 & 999 & 999 & 1000 & 1000 & 1000 \\
\hline 0.55 & 999 & 1000 & 999 & 999 & 999 & 1000 & 999 & 1000 \\
\hline 0.60 & 997 & 1000 & 998 & 999 & 999 & 1000 & 999 & 1000 \\
\hline 0.65 & 997 & 998 & 997 & 998 & 998 & 999 & 998 & 999 \\
\hline 0.70 & 995 & 998 & 995 & 998 & 996 & 999 & 997 & 999 \\
\hline 0.75 & 993 & 995 & 992 & 995 & 997 & 998 & 997 & 998 \\
\hline 0.80 & 992 & 995 & 988 & 994 & 995 & 998 & 994 & 998 \\
\hline 0.85 & 993 & 995 & 987 & 991 & 993 & 997 & 994 & 997 \\
\hline 0.90 & 991 & 995 & 985 & 991 & 991 & 994 & 991 & 997 \\
\hline 0.95 & 989 & 994 & 982 & 991 & 987 & 993 & 988 & 996 \\
\hline 1.00 & 989 & 993 & 985 & 990 & 989 & 996 & 988 & 995 \\
\hline
\end{tabular}


Table 16: Number of series (out of 1000) for which linearity is rejected, Model 11

\begin{tabular}{|c|c|c|c|c|c|c|c|c|}
\hline \multirow[b]{2}{*}{$\lambda$} & \multicolumn{4}{|c|}{ OLS } & \multicolumn{4}{|c|}{ GLS } \\
\hline & AIC95 & AIC90 & BIC95 & BIC90 & AIC95 & AIC90 & BIC95 & $\overline{\text { BIC90 }}$ \\
\hline 0 & 947 & 968 & 956 & 975 & 945 & 970 & 950 & 976 \\
\hline 0.05 & 922 & 948 & 938 & 957 & 938 & 967 & 945 & 974 \\
\hline 0.10 & 872 & 915 & 884 & 927 & 930 & 958 & 941 & 965 \\
\hline 0.15 & 837 & 886 & 840 & 884 & 917 & 955 & 931 & 964 \\
\hline 0.20 & 824 & 876 & 805 & 868 & 902 & 950 & 920 & 957 \\
\hline 0.25 & 816 & 876 & 792 & 852 & 886 & 940 & 905 & 945 \\
\hline 0.30 & 826 & 880 & 794 & 850 & 865 & 921 & 880 & 934 \\
\hline 0.35 & 839 & 883 & 798 & 851 & 831 & 897 & 841 & 903 \\
\hline 0.40 & 848 & 889 & 797 & 850 & 790 & 862 & 798 & 872 \\
\hline 0.45 & 856 & 899 & 800 & 857 & 762 & 837 & 763 & 834 \\
\hline 0.50 & 870 & 899 & 810 & 850 & 754 & 829 & 742 & 813 \\
\hline 0.55 & 872 & 901 & 815 & 849 & 755 & 832 & 711 & 801 \\
\hline 0.60 & 880 & 909 & 821 & 859 & 739 & 819 & 698 & 783 \\
\hline 0.65 & 883 & 913 & 823 & 867 & 740 & 806 & 691 & 769 \\
\hline 0.70 & 891 & 919 & 828 & 869 & 752 & 815 & 689 & 770 \\
\hline 0.75 & 899 & 922 & 839 & 876 & 759 & 817 & 698 & 770 \\
\hline 0.80 & 901 & 927 & 841 & 883 & 766 & 833 & 699 & 775 \\
\hline 0.85 & 907 & 929 & 852 & 884 & 791 & 846 & 724 & 781 \\
\hline 0.90 & 911 & 936 & 858 & 891 & 809 & 848 & 745 & 793 \\
\hline 0.95 & 916 & 940 & 863 & 894 & 819 & 855 & 757 & 803 \\
\hline 1.00 & 924 & 945 & 870 & 902 & 834 & 867 & 766 & 813 \\
\hline
\end{tabular}


Table 17: Number of series (out of 1000) for which linearity is rejected, Model 12

\begin{tabular}{|c|c|c|c|c|c|c|c|c|}
\hline \multirow[b]{2}{*}{$\lambda$} & \multicolumn{4}{|c|}{ OLS } & \multicolumn{4}{|c|}{ GLS } \\
\hline & AIC95 & AIC90 & BIC95 & BIC90 & AIC95 & AIC90 & BIC95 & $\overline{\text { BIC90 }}$ \\
\hline 0 & 981 & 992 & 988 & 994 & 970 & 981 & 973 & 984 \\
\hline 0.05 & 977 & 989 & 983 & 994 & 962 & 976 & 968 & 979 \\
\hline 0.10 & 966 & 984 & 973 & 988 & 958 & 973 & 963 & 977 \\
\hline 0.15 & 958 & 975 & 963 & 980 & 945 & 968 & 949 & 971 \\
\hline 0.20 & 943 & 969 & 949 & 973 & 934 & 962 & 942 & 967 \\
\hline 0.25 & 937 & 958 & 937 & 962 & 923 & 956 & 933 & 960 \\
\hline 0.30 & 922 & 948 & 926 & 953 & 912 & 945 & 922 & 949 \\
\hline 0.35 & 913 & 942 & 917 & 940 & 902 & 939 & 913 & 943 \\
\hline 0.40 & 899 & 937 & 902 & 932 & 887 & 928 & 900 & 932 \\
\hline 0.45 & 886 & 931 & 889 & 927 & 875 & 921 & 886 & 927 \\
\hline 0.50 & 873 & 927 & 877 & 920 & 854 & 909 & 870 & 915 \\
\hline 0.55 & 866 & 920 & 863 & 911 & 834 & 897 & 853 & 905 \\
\hline 0.60 & 860 & 912 & 853 & 901 & 815 & 881 & 836 & 890 \\
\hline 0.65 & 848 & 913 & 834 & 901 & 798 & 871 & 818 & 879 \\
\hline 0.70 & 839 & 906 & 829 & 895 & 779 & 854 & 797 & 864 \\
\hline 0.75 & 833 & 903 & 820 & 888 & 766 & 849 & 783 & 861 \\
\hline 0.80 & 822 & 896 & 808 & 878 & 758 & 838 & 771 & 849 \\
\hline 0.85 & 819 & 892 & 799 & 871 & 747 & 825 & 760 & 839 \\
\hline 0.90 & 824 & 889 & 803 & 871 & 739 & 825 & 747 & 830 \\
\hline 0.95 & 826 & 882 & 802 & 865 & 733 & 824 & 744 & 822 \\
\hline 1.00 & 821 & 878 & 796 & 861 & 745 & 823 & 747 & 815 \\
\hline
\end{tabular}


Table 18: Number of series (out of 1000) for which linearity is rejected, Model 13

\begin{tabular}{|c|c|c|c|c|c|c|c|c|}
\hline \multirow[b]{2}{*}{$\lambda$} & \multicolumn{4}{|c|}{ OLS } & \multicolumn{4}{|c|}{ GLS } \\
\hline & AIC95 & AIC90 & BIC95 & BIC90 & AIC95 & AIC90 & $\overline{\text { BIC95 }}$ & $\overline{\text { BIC90 }}$ \\
\hline 0 & 991 & 996 & 994 & 997 & 985 & 987 & 987 & 988 \\
\hline 0.05 & 991 & 996 & 991 & 996 & 983 & 987 & 986 & 988 \\
\hline 0.10 & 990 & 995 & 988 & 991 & 983 & 987 & 983 & 989 \\
\hline 0.15 & 990 & 994 & 991 & 994 & 982 & 986 & 981 & 988 \\
\hline 0.20 & 988 & 994 & 990 & 993 & 980 & 985 & 982 & 989 \\
\hline 0.25 & 988 & 996 & 989 & 994 & 976 & 982 & 982 & 988 \\
\hline 0.30 & 986 & 995 & 990 & 996 & 970 & 980 & 975 & 988 \\
\hline 0.35 & 983 & 993 & 990 & 996 & 965 & 979 & 968 & 985 \\
\hline 0.40 & 982 & 990 & 988 & 996 & 965 & 978 & 970 & 983 \\
\hline 0.45 & 980 & 988 & 986 & 992 & 965 & 978 & 969 & 984 \\
\hline 0.50 & 981 & 986 & 988 & 992 & 961 & 975 & 966 & 981 \\
\hline 0.55 & 974 & 988 & 981 & 992 & 956 & 974 & 962 & 980 \\
\hline 0.60 & 966 & 983 & 974 & 988 & 953 & 972 & 961 & 977 \\
\hline 0.65 & 961 & 975 & 971 & 982 & 950 & 970 & 956 & 973 \\
\hline 0.70 & 955 & 972 & 968 & 979 & 942 & 965 & 951 & 969 \\
\hline 0.75 & 955 & 970 & 965 & 978 & 933 & 955 & 941 & 962 \\
\hline 0.80 & 946 & 967 & 959 & 976 & 922 & 954 & 928 & 961 \\
\hline 0.85 & 942 & 961 & 955 & 972 & 916 & 949 & 921 & 955 \\
\hline 0.90 & 932 & 957 & 944 & 966 & 907 & 944 & 915 & 953 \\
\hline 0.95 & 920 & 950 & 936 & 960 & 905 & 933 & 911 & 943 \\
\hline 1.00 & 915 & 942 & 934 & 956 & 895 & 930 & 904 & 937 \\
\hline
\end{tabular}


Table 19: Number of series (out of 1000) for which linearity is rejected, Model 14

\begin{tabular}{|c|c|c|c|c|c|c|c|c|}
\hline \multirow[b]{2}{*}{$\lambda$} & \multicolumn{4}{|c|}{ OLS } & \multicolumn{4}{|c|}{ GLS } \\
\hline & AIC95 & AIC90 & BIC95 & BIC90 & AIC95 & AIC90 & $\overline{\text { BIC95 }}$ & $\overline{\text { BIC90 }}$ \\
\hline 0 & 907 & 940 & 913 & 946 & 946 & 967 & 957 & 969 \\
\hline 0.05 & 908 & 947 & 916 & 951 & 946 & 967 & 959 & 969 \\
\hline 0.10 & 911 & 951 & 921 & 956 & 944 & 966 & 955 & 969 \\
\hline 0.15 & 912 & 953 & 929 & 961 & 945 & 965 & 955 & 969 \\
\hline 0.20 & 919 & 950 & 937 & 961 & 941 & 966 & 952 & 969 \\
\hline 0.25 & 925 & 956 & 945 & 969 & 940 & 966 & 949 & 970 \\
\hline 0.30 & 927 & 959 & 946 & 974 & 939 & 965 & 948 & 970 \\
\hline 0.35 & 930 & 962 & 950 & 975 & 937 & 963 & 947 & 968 \\
\hline 0.40 & 936 & 964 & 955 & 977 & 936 & 959 & 948 & 967 \\
\hline 0.45 & 939 & 962 & 955 & 973 & 932 & 958 & 945 & 966 \\
\hline 0.50 & 935 & 961 & 953 & 972 & 932 & 956 & 945 & 965 \\
\hline 0.55 & 932 & 961 & 949 & 969 & 928 & 953 & 943 & 962 \\
\hline 0.60 & 927 & 958 & 947 & 966 & 921 & 952 & 937 & 964 \\
\hline 0.65 & 921 & 957 & 943 & 966 & 916 & 953 & 932 & 964 \\
\hline 0.70 & 918 & 955 & 936 & 963 & 914 & 951 & 931 & 962 \\
\hline 0.75 & 910 & 952 & 928 & 962 & 914 & 951 & 931 & 963 \\
\hline 0.80 & 895 & 941 & 919 & 955 & 911 & 947 & 929 & 960 \\
\hline 0.85 & 889 & 932 & 909 & 950 & 908 & 945 & 925 & 959 \\
\hline 0.90 & 889 & 925 & 902 & 943 & 904 & 945 & 921 & 959 \\
\hline 0.95 & 878 & 920 & 889 & 937 & 900 & 944 & 917 & 956 \\
\hline 1.00 & 876 & 919 & 880 & 931 & 896 & 942 & 915 & 954 \\
\hline
\end{tabular}




\section{References}

[1] Box, G.E.P. and D.R. Cox (1964), An Analysis of Transformations, Journal of the Royal Statistical Society, Series B, 26, 211-43.

[2] Franses, P.H. and G. Koop (1998), On the Sensitivity of Unit Root Inference to Nonlinear Data Transformations, Economics Letters 59, 7-15.

[3] Franses, P.H. and M. McAleer (1998), Testing for Unit Roots and Non-Linear Transformations, Journal of Time Series Analysis 19, 147-64.

[4] Franses, P.H. and R. Paap (1999), Does Seasonality Change Inference from Markov Switching Regime Models?, Journal of Macroeconomics, to appear.

[5] Ghysels, E., C.W.J. Granger and P.L.Siklos (1996), Is Seasonal Adjustment a Linear or Nonlinear Data-Filtering Process?, Journal of Business and Economic Statistics 14, 374-86.

[6] Granger, C.W.J. and T. Teräsvirta (1993), Modelling Nonlinear Economic Relationships, Oxford University Press, Oxford.

[7] Granger, C.W.J. and J.J. Hallman (1991), Nonlinear Transformations of Integrated Time Series, Journal of Time Series Analysis 12, 207-24.

[8] Hamilton, J.D. (1989), A New Approach to the Economic Analysis of Nonstationary Time Series Subject to Changes in Regime, Econometrica 57, 357-84.

[9] Teräsvirta, T. (1994), Specification, Estimation, and Evaluation of Smooth Transition Autoregressive Models, Journal of the American Statistical Association 89, 208-18.

[10] Tong, H. (1990), Non-Linear Time Series: A Dynamical System Approach, Oxford University Press. 